\title{
VIOLENCIA, CENSURA E LOUCURA: A SEMENTE DE GIANFRACESCO GUARNIERI
}

Resumo: $O$ presente estudo analisa a peça de teatro A Semente (1961), do dramaturgo Gianfrancesco Guarnieri. A peça foi censurada em 26/04/1961 e liberada dois dias depois após uma comissão de intelectuais considerarem que a peça não poderia ser acusada de subversiva, pois ela era "reveladora de um problema tremendamente humano na sua grandiosidade" (ÚLTIMA HORA, 27/04/1961). Vemos neste texto que o ambiente de violência, embargo e loucura circundam os anos 60 , por conta dos antagonismos promovidos pela guerra fria e a luta contra a "subversão". No espetáculo, Guarnieri consegue colocar o operariado no palco e discutir questões fundamentais sobre a resistência e a necessidade de lutar pelos direitos humanos.

Palavras-chave: Violência. Censura. Locura. A Semente.
Augusto SARMENTO-PANTOJA

Faculdade de Ciências da Linguagem/UFPA augustos@ufpa.br

Resumé: Cette étude analyse le jeu $A$ Semente (1961), du dramaturge Gianfrancesco Guarnieri. La pièce a été la censure sur 26/04/1961 et libéré deux jours plus tard, après un comité d'intellectuels considèrent que la pièce ne pouvait pas être accusé de subversif parce qu'il était "reveladora de um problema, tremendamente humano na sua grandiosidade" (ÚLTIMA HORA, 27/04/1961). Nous voyons dans ce texte que l'environnement de la violence, de l'embargo et de la folie entourant les années 60, en raison de l'antagonisme promu par la guerre froide et la lutte contre la "subversion". Dans le spectacle, Guarnieri peut mettre la classe ouvrière sur la scène et de discuter des questions fondamentales sur la force et la nécessité de lutter pour les droits humains.

Mots-clés: Violence. Censure. Madness. A Semente. 


\section{Violência, Censura e Loucura}

O terror não é a mesma coisa que a violência; é antes a forma de governo que nasce quando a violência, após destruir todo o poder, não abdica, mas, ao contrário, permanece mantendo todo o controle. Pode-se observar que a eficácia do terror depende quase que inteiramente do grau de atomização social. Todos os tipos de oposição organizada deverão desaparecer para que seja liberada a força total do terror. (...) O clímax do terror é alcançado quando o estado policial começa a devorar os seus próprios filhos, quando o carrasco de ontem torna-se a vítima de hoje. É este o momento quando o poder desaparece inteiramente.

(ARENDT, 2004, p. 35)

O controle produzido pela violência gera na sociedade um estado de terror que circunda o cotidiano das sociedades humanas na contemporaneidade. Tal situação vem sendo discutida abertamente fundamentada no discurso de construção de uma política de não violência. Entretanto, o que encontramos nos ditames da história da humanidade são provas constantes da existência de certa dependência das sociedades para com a manutenção da violência. Isso porque elas legitimam tais procedimentos, muitas vezes sem aceitar que tais práticas geram o terror ante sua população.

Neste trabalho nos dispomos a pensar um contraponto entre a existência de uma sociedade da violência e a sociedade violente constituída por meio de um emaranhado de situações que reprimem e legitimam a violência, justamente pela colaboração desta mesma sociedade que garante condições para o desenvolvimento de práticas de embargo contra todas as formas de resistência, como ocorreu com a peça de teatro A Semente, de Gianfrancesco Guarnieri.

O Brasil, em 1961, vive como boa parte do planeta os efeitos da Guerra Fria, responsável por colocar os países no dilema de tomarem partido de um dos lados da moeda: ou se é capitalista ou socialista. Nesse sentido, em virtude da disputa por territórios, são criados diversos mecanismos de controle social e nos estados "democráticos", onde não encontramos nem guerras, nem conflitos internos, são constituídos órgãos que possam acompanhar mais de perto as produções culturais produzidas. Neste contexto funcionam o 
Departamento de Ordem Política e Social (DOPS) e a Divisão de Diversão Pública. Esses dois órgãos foram os responsáveis pela proibição de A Semente, por considerar que "seu texto, invariavelmente, constitui claro e audacioso incitamento à subversão da ordem pública, objetivando solapar em suas bases a estrutura do regime vigente no país" (DIÁRIO OFICIAL, 26 de abril de 1961).

Carla de Araújo Risso (2013, p. 05), no artigo Semeando a Discórdia: a imprensa e o processo de censura teatral da peça A Semente de Gianfrancesco Guarnieri, observa que a censura aplicada contra o espetáculo repercutiu em vários setores da sociedade paulistana, tanto que dois dias depois da publicação da proibição várias manifestações públicas felicitando o veto da peça vieram a público, como uma carta com 62 assinaturas, em nome das famílias do Sumaré, outra da diretora do Ginásio Boni Consilii, um abaixo assinado com 32 assinaturas das professoras do Curso Primário do Colégio Assunção e da Escola Madre Maria Eugênia, entre outras.

Com isso podemos identificar que os anos "democráticos" anteriores à ditadura brasileira não podem ser confundidos com anos de liberdade, pois a violência da censura aplicada contra a sociedade foi bastante eficaz. Hannah Arendt, em Da Violência, deixa claro como a violência terá sua eficácia medida pela forma como é possível destruir toda e qualquer oposição (atomização) e principalmente, todo e qualquer opositor ao ponto de o vilão sofrer com sua própria vilania.

Essa aceitação da sociedade ao aparato censor do Estado revela o quanto o meio social, de certa maneira, contribui para que a violência se mantenha, pois alimenta e contribui para que o aparelho estatal mantenha o aparato repressivo. De certo modo, esta maneira de conceber a violência nos mostra como a sociedade cria associações biológicas que a justificam. Vejamos o que analisa Hanna Arendt sobre isso:

essa justificativa biológica - da violência - aparentemente tão nova relaciona-se estreitamente aos mais perniciosos elementos de nossas mais antigas tradições do pensamento político. De acordo com o tradicional conceito de poder, equiparado, conforme vimos, à violência, o poder é expansionista por natureza. Tem ele "uma ânsia interior por crescer" e é criativo porque "o instinto que o faz crescer lhe é próprio". Exatamente da mesma maneira como nos domínios da vida orgânica todas as coisas ou

\footnotetext{
${ }^{1}$ JOUVENEL, Bertrand de Du Pouvoir. pp. 114 e 123, 101 - Ibidem, pp. 187 e 188. Respectivamente. 
crescem ou decaem e morrem, também nos domínios das relações humanas o poder pode, como se supõe, manter-se apenas através da sua expansão; de outra maneira, ele se retrairá e morrerá. (2004, p 47)

A violência e o poder têm fundamental relação com as formulações biológicas, o que leva a sua permanência, pois do contrário teríamos sua morte. Contribuindo com essa análise Paulo Sérgio Pinheiro, no artigo Violência, crime e sistemas policiais em países de novas democracias, considera que há a manutenção da violência mesmo após as violações contra os direitos humanos promovidos pelos regimes de exceção.

Ao mesmo tempo em que foram eliminadas as violações mais fortes contra os direitos humanos cometidos pelos regimes militares, os governos civis recém-eleitos não tiveram êxito em proteger os direitos fundamentais de todos os cidadãos. Como consequência, permanece precário o regime da lei em muitos países latino-americanos. No Brasil, assim como em outros lugares, as vítimas não são mais militantes políticos, muitos deles pessoas educadas da classe média, cuja oposição ao regime militar fez com que fossem assassinados ou brutalmente torturados. Hoje em dia, o principal alvo da arbitrariedade policial são os mais vulneráveis e indefesos da sociedade brasileira: o pobre, o trabalhador rural e sindicalistas, grupos minoritários, crianças e adolescentes abandonados, muitos vivendo nas ruas. Muita dessa violência é alimentada por uma discriminação enraizada na sociedade contra os pobres e as minorias raciais, que são em sua maioria vítimas de homicídio. A prisão arbitrária e a tortura são práticas policiais muito comuns. (PINHEIRO, 1997, 44)

Walter Benjamin em Por uma crítica de la violencia, aponta dois tipos diferentes de violência, mas ao mesmo tempo complementares: a histórica e a sancionada. Ele procura estabelecer uma distinção entre elas:

Se establece una distinción entre la violencia históricamente reconocida, es decir la violencia sancionada como poder, y la violencia no sancionada. Si los análisis que siguen parten de esta distinción, ello naturalmente no significa que los poderes sean ordenados y valorados de acuerdo con el hecho de que estén sancionados o no. Pues en una crítica de la violencia no se trata de la simple aplicación Del criterio del derecho positivo, sino más bien de juzgar a su vez al derecho positivo. Se trata de ver qué consecuencias tiene, para la esencia de la violencia, el hecho mismo de que sea posible establecer respecto de ella tal criterio o diferencia. $\mathrm{O}$, en otras palabras, qué consecuencias tiene el significado de esa distinción. Puesto que veremos en seguida que esa distinción del derecho positivo tiene sentido, está plenamente fundada en sí y no es substituible por ninguna otra; pero con ello mismo se arrojará luz sobre esa esfera en la cual puede realizarse dicha distinción. (BENJAMIN, 1995, p. 28) 
Entendemos que as formas de violência destacadas por Benjamin podem ser interessantes para observarmos tanto a indistinção delas quanto para elencarmos algumas questões fundamentais para o entendimento das teorizações sobre a memória histórica. Em relação a esta memória histórica Walter Benjamin contribui com um debate frutífero para a crítica da violência, isso porque sinaliza a multiplicidade de formas e caracterizações da mesma, apontando situações em que os próprios mecanismos de repressão são reconhecidos e legalizados no desenvolvimento da violência, quase sempre por representar a instalação de embargos e censuras contra elementos de uma sociedade biologicamente enferma que precisa ser colocada na linha.

A necessidade de colocar na linha pode ser evidenciada por um discurso de agravo à censura contra a peça $A$ Semente, quando encontramos o Frei Clemente Costa Neves, Diretor do Colégio Santo Alberto dos Padres Carmelitas, considerando que ele "escreveu para enaltecer a têmpera e o caráter do Diretor Substituto da Divisão de Diversões Públicas, um homem capaz de se opor 'à onda de anarquia e de rebelião, que avassala o mundo civilizado" (RISSO, 2013, p. 6). Identificamos este discurso muito próximo aos regimes ditatoriais que justificam a utilização de um poder daimônico, exercido quase sempre pelo ditador, alicerçado por uma permissividade de seus atos justamente por se encontrar em uma condição de poder sancionado por uma sociedade que, aliciada ou convencida, "coopera" e "autoriza" o desenvolvimento e a manutenção do poder pelas vias da força e da violência, como pontua Hannah Arendt em Origens do Totalitarismo. Para ela

A persrguição de grupos impotentes, ou em processo de perder o poder, pode não constituir um espetáculo agradável, mas no decorrer da mesquinez humana. O que faz com que os homens obedeçam ou tolerem o poder e, por outro lado, odeiem aqueles que dispõem ds riqueza sem o poder é a idéia de que o poder tem uma determinada função e certa utilidade geral. Até mesmo a exploração e a opressão podem levar a sociedade ao trabalho e ao estabelecimento de algum tipo de ordem. Só a riqueza sem o poder ou o distanciamento altivo do poder que, embora poderoso, não exerce atividade política são considerados parasitas e revoltantes, porque nessas condições desaparecem os últimos laços que mantêm ligações entre os homens. A riqueza que não explora deixa de gerar até memso a relação existente entre o explorador e o explorado; o alheamento sem política indica a falta do menor interesse do opressor pelo oprimido. (ARENDT, 1998, p. 25) 
A necessidade de manter o poder e a violência insufla os regimes da necessidade de produzir diversas formas de embargo contra a sociedade, para que se possa aniquilar qualquer forma de resistência. Nestes termos, encontramos nas palavras de Hannah Arendt um forte questionamento sobre o estatuto da anistia, pois similarmente ao que ocorre com a relação opressor/oprimido, descrito pela autora, observamos também no teatro de Gianfrancesco Guarnieri em A Semente (1961). Arendt destaca um incômodo para com os procedimentos de esquecimento produzidos pelas anistias, isso porque entendemos que o desinteresse pelos dramas vividos pelos oprimidos diante da percepção do terror promovido pelos opressores gera as condições necessárias para que as atrocidades promovidas pelos regimes ditatoriais também fiquem no limbo.

Conseguimos aproximar agora violência e censura e podemos caracterizar este último como um procedimento fundamental à propagação da violência, já que garante o controle das massas revoltosas. Dessa maneira, para Benjamin não deveríamos realizar uma distinção entre as formas de violência autorizadas e não autorizadas, seja pelo Estado, seja pela sociedade ou pela família, pois necessariamente o ponto fulcral da crítica da violência não seria determinar se há a permissividade para com o desenvolvimento dela, mas sim os efeitos de seus usos.

Pues en el ejercicio del poder de vida y muerte el derecho se confirma más que en cualquier otro acto jurídico. Pero en este ejercicio, al mismo tiempo, una sensibilidad más desarrollada advierte con máxima claridad algo corrompido en el derecho, al percibir que se halla infinitamente lejos de condiciones en las cuales, en un caso similar, el destino se hubiera manifestado en su majestad. Y el intelecto, si quiere llevar a término la crítica tanto de la violencia que funda el derecho como la de la que lo conserva, debe tratar de reconstruir en la mayor medida tales condiciones. (BENJAMIN, 1995, p.44)

Neste sentido o direito e o homem mantêm as condições sobre o exercício do poder de vida ou de morte. No caso dos regimes de exceção isso fica mais latente uma vez que o poder exercido contra grupos sociais determinados viola toda e qualquer liberdade de ação ou decisão, promovidos pela opressão "autorizada", mesmo quando entendamos a impossibilidade de aceitação do inteligível binômio violência e poder autorizados. A autorização social da violência não a isenta de sua associação ao horror, isso porque 
Toda violencia es, como medio, poder que funda o conserva el derecho. Si no aspira a ninguno de estos dos atributos, renuncia por si misma a toda validez. Pero de ello se desprende que toda violencia como medio, incluso en el caso más favorable, se halla sometida a la problematicidad del derecho en general (BENJAMIN, 1995, p. 47).

Por isso, podemos compreender que a violência não poderá decorrer de uma ausência do contrato jurídico, no sentido da existência de uma aceitação da mesma. Por fim fica evidente que a íntima relação entre as formas de aceitação da violência nos aproxima ao conceito de memória histórica, porque toda violência possui uma ambivalência fundamental a qual aproxima opressores e oprimidos em um "pacto" de aceitação de uma história que reflete a memória coletiva identificada como representacional de uma comunidade.

\section{Sementes de uma história}

Bakhtin aponta o cronótopo como a fusão entre tempo e espaço, além disso observa que tais elementos na narrativa literária, apresentam seu valor expressivo como forma de manifestação da realidade. Neste sentido, recorremos ao artigo de Isabelle Van PeteghemRouffineau, Alice Walker ou l'écriture de La résilience, para discutir tal posição sobre o cronótopo, associando-o a um traumatismo original, isso porque tal fusão gera um conflito sobre o reconhecimento de um tempo e um espaço e a identificação deste com a sua memória histórica.

Le chronotope permet la fusion des indices spatiaux et temporels en un tout intelligible et concret : Le Sud renvoie à une époque, à un âge d'or révolu pour les uns, à un âge de plomb pour les autres, et à un lieu que l'on doit fuir mais qui contient la résolution du conflit. Il symbolise le lieu du traumatisme originel. (PETEGHEM-ROUFFINEAU, 2006, p 25)

Sabemos que o termo semente revela uma tradução ligada a un facto iniciale que de uma leitura que se pretende germinar e florescer. O enredo da obra A Semente, de Gianfrancesco Guarnieri, também possui esse liame de florescimento de nascence: origem de um sentimento de revolta dos oprimidos para com os opressores, retrata conjunturas político-sociais que convencem algumas camadas da sociedade a se organizarem para combater e resistir aos sistemas ditatoriais. A peça de teatro recapitula de maneira bem 
acentuada uma vertente fundamental da resistência política, uma vez que narra a tentativa do operário Agileu de mobilizar sua classe em busca de reivindicar melhores condições de trabalho durante a ditadura de Vargas. Mesmo sendo encenada em tempos de “democracia”, o fato de a peça possibilitar a reflexão sobre a necessidade de mobilização popular e organização da massa trabalhadora foi determinante para arregimentar apoio de vários grupos sociais contra à censura prévia do espetáculo. O conservadorismo das instituições e a forma como essas moções de apoio foram apresentadas revelam que nos anos 60 estávamos, antes de 64, sob um regime de opressão das liberdades.

A Semente não demarca claramente o tempo histórico a ser encenado e, por isso, consideramos haver ali um tempo imemorial distante de uma realidade histórica. Ainda assim, a peça é responsável por expor como se dá a repressão e o poder produzido sobre os oprimidos.

los refugiados (cuyo número nunca ha dejado de crecer durante nuestro siglo, hasta incluir hoy día a una parte no despreciable de la humanidad) representen, en el ordenamiento de la Nación-Estado moderna, un elemento tan inquietante, es debido sobre todo aquel, al romperse la continuidad entre hombre y ciudadano, entre nacimiento y nacionalidad, ellos ponen en crisis la ficción originaria de la soberanía moderna (AGANBEN, 1996, p. 45)

A crise da ficção originária da soberania moderna será o elemento de liame entre a obra de Guarnieri e concepção de uma memória histórica, deixando nítida a presença de diversas situações subumanas de vida do proletariado, tais como a alta carga horária de trabalho, a exploração infantil e a depressão. Soma-se a toda essa estrutura, a tentativa de Agileu liderar diversas revoltas dentro da fábrica a fim de se obter melhores condições de vida. Mas esse desejo fracassa diversas vezes, seja pela falta de adesão à causa, seja pelo silenciamento decorrente da repressão política.

É nas atitudes desta personagem que inquietação diante de uma realidade de exploração se mostra mais presente. Temos diante de nós um operário que acredita que tal situação precisa ser transformada, isto é, não deve ser aceita passivamente pelo povo. Vejamos o diálogo a seguir:

AGILEU - A situação está bem ruim, hein, avó?!

VELHA - A gente acostuma. 
AGILEU - Pois não devia acostumá! (GUARNIERI, 1978, p. 29)

As mobilizações em busca de construir a resistência à exploração dos trabalhadores daquela fábrica ficam evidentes quando começam a se concretizar a partir do episódio em que Tonico, filho do operário Américo, sofre um acidente na fábrica. No fragmento a seguir fica nítida a proposta de Agileu para que a classe operária se mobilize caso Tonico morra: "AGILEU - Se o garoto morre, a gente levanta a classe operária toda! Isso precisa de uma demonstração monstro! " (GUARNIERI, 1978, p. 38).

Esse processo de questionamento de uma realidade histórica em relação ao que foi imposto é perceptível ainda no final de uma reunião do sindicato, em que são expostas as reivindicações para que a proposta dos patrões em relação à morte do menino não seja apenas para ele, mas possa ser pautada nas necessidades do coletivo. Vejamos a passagem a seguir: "ASSISTENTE - O que ele disse. Pagamento imediato do adicional, indenização ao filho do Américo, proteção do menor, melhores condições de trabalho... há muitos filhos mortos... mulheres doentes... muitos filhos comendo terra..." (GUARNIERI, 1978, p. 5960). A posição de Agileu de criação de um comício e protesto em relação ao tratamento recebido aos familiares do garoto Tonico não é entendida, nem apoiada pelos seus companheiros. Para eles não é hora de protestar contra as péssimas condições de trabalho. Mas Agileu continua firme no seu posicionamento de resistência e assevera:

É preciso! É preciso fazê comício a todo instante. (...). Vivem falando em precipitação, em falta de condições. A reboque de tudo, do próprio medo. Só porque tem um dedo-duro qualquer, porque dois ou três companheiros foram presos, é o pânico? Nada disso, infeliz! A hora é de ação e de ação rápida.

(...)

A hora é de a gente ir pra fábrica. Esclarecer essa gente. Experimentá-los nas lutas. Demonstrar em massa nosso poder! (GUARNIERI, 1978, p. 57)

Entretanto com a morte de Tonico e de Américo (filho e pai) temos a motivação necessária para fortalecer o movimento de resistência dos trabalhadores em busca de justiça, pois "Nós responsabilizaremos a empresa pela morte do Tonico e do Américo! Nosso movimento é de protesto!" (GUARNIERI, 1978, p. 106). O apoio às convicções de Agileu serão maiores a cada momento, ao ponto de os trabalhadores realizarem uma passeata a qual potencializará a repressão voraz contra os trabalhadores. 
Quando o gerente da fábrica, preocupado com a iminência de greves, tenta colocar os operários contra Agileu afirmando que a greve é ilegal, o operário, respaldado pelos episódios da morte de Tonico e o suicídio de Américo, argumenta fervorosamente contra o gerente "E a morte de Toniquinho, é legal? E a falta de pagamento de adicional é legal? É legal esses menores trabalhando tempo extra? E a morte do Américo? Que acabou de dor e de miséria, por falta de esperança? Do Américo que morreu batendo nas máquinas! É legal?!" (GUARNIERI, 1978, p. 108-109)

Percebendo que seu argumento conseguiu traduzir o que os outros operários sentiam a respeito de toda aquela situação de exploração trabalhista, Agileu começa a liderar a manifestação após o gerente ter se retirado sob vaias. Como pode ser observado em: "Vamos lá, gente, pega as faixas. Vamos receber os outros já de faixa aberta. Os manifestos estão aí, gente atira pro povo, com fé, hein! ...” (GUARNIERI, 1978, p. 110).

Na obra A Semente, alguns operários descontentes com a realidade trabalhista e social imposta já estavam cientes do perigo da repressão e por isso pensavam com cautela antes de se mobilizarem. No trecho a seguir é perceptível o alerta dado por Cipriano a Agileu de uma possível repressão da polícia, depois de ela já ter prendido a mulher deste último: "Estou te entendendo, Agileu. Mas eu não posso. E se eles te pegam agora, te amassam de pancada e você fala? Ninguém está livre disso. É melhó pra você ficá de fora. Me entende, vai!" (GUARNIERI, 1978, p. 36)

Em outro fragmento da obra fica nítida a manipulação de depoimento que a polícia realiza para tentar reprimir o movimento dos operários a partir da deturpação da declaração de Rosa Carraro, esposa de Agileu, em que esta afirma não ter conhecimento da participação do marido no Partido, mas acaba assinando papéis em branco e que depois serão aproveitados para embasar a acusação de envolvimento em atividades subversivas:

DELEGADO - Pois muito bem. E a senhora afirma não saber qual o caráter dessas reuniões.

(...)

DELEGADO - Sendo assim, a senhora não poderá negar que reuniões tinham caráter subversivo...

(...)

DELEGADO - (...) nosso datilógrafo está ocupadíssimo. A senhora terá de esperar aqui bastante tempo, talvez até amanhã. Então? 
ROSA - Ah! Tô cheia, sabe? Dá aqui! (Assina as folhas em branco.) (GUARNIERI, 1978, p. 50-52)

Eis a seguir o resultado de tal manobra policial, como forma de enfraquecer o movimento atribuindo a Agileu a imagem de uma pessoa descontrolada e agressiva, como costumeiramente são retratados os militantes da esquerda no discurso do Estado:

JOFRE - (...) Rosa Carraro declarou às autoridades que seu marido é o principal responsável pelos movimentos subversivos que vêm ocorrendo, dentre os quais a greve geral de metalúrgicos, bem como pelos movimentos pró-paz dos bairros do Brás e da Mooca (...) Rosa Carraro declarou ser insuportável o convívio com Agileu. Queixou-se de sofrer maus tratos do marido que, alcoolizado, chegou mesmo a atentar contra a sua vida! (GUARNIERI, 1978, p. 79)

A partir de alguns fragmentos da peça, é perceptível a repressão policial logo quando os operários começam a protestar pelas mortes de Américo e Tonico: “Tá tudo cercado! Tão jogando gás! (...) Olha lá, é um carro de choque! (...) Tão atirando pedra! (...) Ouve-se uma rajada de metralhadora. " (GUARNIERI, 1978, p. 117-118)

Com o protesto reprimido, o delegado a fim de desvirtuar a imagem de Agileu como líder, resolve esclarecer para o operário qual o plano traçado para desmantelar o movimento, perceptível a seguir: "Com tipos da sua espécie há dois caminhos: o fuzilamento sumário, infelizmente impraticável; ou vossa autodestruição que, pensando bem, é o que mais me agrada. É o mais inteligente, o mais humano...” (GUARNIERI, 1978, p. 121)

Logo após ser solto, Agileu deixa claro em seu discurso que a finalidade de ele ter sido libertado era para "me fazer passar por traidor... Prenderam mais de trinta companheiros... Jofre e Cipriano também... Na fábrica, estão certos de que fui eu que delatei..." (GUARNIERI, 1978, p. 139). A manipulação dos depoimentos e das informações sobre os militantes e os próprios movimentos de resistência ficam evidentes no texto. Essa é uma estratégia usada não só para desarticular as oposições: ela ajuda a construir uma falsa imagem das ações dos militantes. A delação não é premiada, mas contribui para desvirtuar as práticas da resistência e convencer a opinião pública, na construção de uma espécie de memória amnésica às avessas. 
Partindo do fato de que a memória amnésica se caracteriza pela repetição do evento traumático por não ter sido recalcado ${ }^{2}$ na psique do traumatizado, na obra $A$ Semente, por meio do personagem Américo, pai de Tonico, encontramos a representação de tal sequela, em decorrência do trauma vivido pelo operário: a morte de seu filho. Os trechos a seguir dizem respeito ao conjunto de alucinações que o operário manifesta durante um expediente de trabalho na fábrica:

AMÉRICO - As máquinas, pelo amor de Deus. As máquinas, pára! Pára a engrenagem. Olha o braço. Olha o braço dele!

(...)

AMÉRICO - Olha o braço. O bracinho dele!

AMÉRICO - Aguenta, minha esperança, aguenta. Só um pouco. Já pára! Já pára tudo. Não grita filho. Não grita... já parou, tá parando...

(...)

AMÉRICO - Olha lá o que foi. Olha lá, tá sangrando! Vamo tirá ele de lá. Vamo tirá. Ajuda baiano, ajuda!

(...)

AMÉRICO - Não. Eu. Eu vou. Calma, filho. Aguenta um pouco. Que nem homem. Como te ensinei, hein? Como te ensinei!

(...)

AMÉRICO - Eu não consigo chegá lá. Num consigo. Me acode, minha Nossa Senhora, me acode! Eu não consigo chegá lá! (GUARNIERI, 1978, p. 97-98)

Dessa forma, esse reviver alucinatório que se reporta à retomada de fatos inerentes à cena traumática da morte de Tonico - quando seu braço ficou preso nas máquinas, quando Américo pediu que parassem as máquinas e quando este tenta alcançar o menino a fim de tirar seu braço das máquinas - irá caracterizar a memória amnésica em Américo, mas também todo o descaso que o empresariado possui em relação à vida e à saúde dos seus trabalhadores.

Em A Semente, a não superação das perdas são nítidas, podendo ser observadas, por exemplo, a partir da psique de Américo que não se conforma com a morte do filho. Entretanto, na fábrica gesta um pacto de silenciamento sobre essa atrocidade, inviabilizando que os trabalhadores pudessem exigir melhorias. Isso pode ser perceptível logo após o velório de Tonico, quando Américo vai trabalhar na fábrica e este demonstra a

\footnotetext{
${ }^{2}$ Recalque, segundo Maldonado e Cardoso (2009), é a operação pela qual o indivíduo procura repelir ou manter no inconsciente as representações ligadas ao afluxo pulsional excessivo - o trauma -; o que torna impossível a assimilação da vivência traumática como um fato já ocorrido, instalando um presente contínuo.
} 
dificuldade de retomar sua rotina sem a presença do filho: "AMÉRICO - Primeiro almoço que faço sem meu filho perto pedindo a sobremesa..." (GUARNIERI, 1978, p. 89). Todavia, todas as atividades da fábrica voltam ao normal.

Outro momento em que é perceptível a não superação da perda por parte de Américo é quando este começa a apresentar alucinações que dão a garantia de que Tonico ainda está vivo: "AMÉRICO - (...) Olha lá o Toniquinho, tá subindo sempre. Sobe que nem louco! Ah, menino, o trabalho que você dá! Toniquinho não sobe mais... Está no andaime!" (GUARNIERI, 1978, p. 99). Mesmo quando cessados esses delírios e com Américo reconhecendo que Tonico já não está vivo ("Tonico! Ah!... É mentira, mentira desgraçada! " (Idem, p. 99) o operário deseja vê-lo novamente, mesmo que seja através de alucinações ("Eu quero vê!... de novo!” (Idem, p. 99), evidenciando, dessa forma, a não superação das perdas, principalmente diante do silenciamento constituído por uma "exigência" de esquecimento, como nas políticas de esquecimento desenvolvidas pelo Estado brasileiro em relação à ditadura civil-militar, por exemplo, com a lei da Anistia.

A obra de Guarnieri mostra como existe certo desalento em relação aos movimentos de resistência, tanto que notamos na narrativa, quatro passagens fundamentais, capazes de esclarecer esse sentimento: temos Rosa, enganada pela repressão, obrigada a assinar uma confissão em um papel em branco; Américo, derrotado pela impossibilidade de aceitar a morte do filho, gerando um estado de loucura que o leva ao suicídio; João, desolado com a morte de sua esposa grávida em uma passeata; e Agileu que acaba acusado injustamente de traição e delação das ações do partidão.

Esses são os reflexos de um Estado autoritário que não para de construir estratagemas para manter o cerco contra os movimentos de resistência e demarcar seu território de opressão.

\section{REFERÊNCIAS}

ARENDT, Hannah. Origens do totalitarismo. Tradução: Roberto Ramos. São Paulo: Companhia das Letras, 1989. 
. Da violência. Tradução: Maria Claudia Drummond. São Paulo: Sabotagem, 2001. Disponível em: www.4shared.com/get/J1Stz770/Hannah_Arendt__Sobre_la_viole.html

AGANBEM, Giorgio. Política del exílio. Traducido por Dante Bernardi. Archipiélago. Cuadernos de crítica de la cultura. Barcelona, № 26-27, 1996

BENJAMIN, Walter. Por uma crítica de la violencia. Tradução: Héctor A. Murena, Buenos Aires: Editorial Leviatán, 1995. Original: Zur Kritik der Gewalt, 1921.

BAKHTINE, Mikhail. Esthétique et théorie du roman, 1978, p. 238

PETEGHEM-ROUFFINEAU, Isabelle Van. Alice Walker ou l'écriture de la résilience. Études littéraires, vol. 38, $\mathrm{n}^{\circ}$ 1, 2006, p. 25-36. Capturado em 27/06/2011. Disponível em: http://id.erudit.org/iderudit/014819ar

PINHEIRO, Paulo Sérgio. Violência, crime e sistemas policiais em países de novas democracias. Tempo sociedade. Vol. 9. №. 1. São Paulo. May. 1997. Disponível em: http://www.scielo.br/scielo.php?pid=S0103-20701997000100003\&script=sci_arttext 